\title{
Illumination of a production facility for communication and electric power cables
}

\author{
Cristian Tsakiris ${ }^{1}$, Cristin Bigan ${ }^{1,}{ }^{*}$, and Valentin Panduru ${ }^{1}$ \\ ${ }^{1}$ Ecological University of Bucharest, Faculty of Environment and Management Engineering, Romania
}

\begin{abstract}
Sight represents $90 \%$ of our sensory everyday life. In specific work conditions, like long distance communication and electric power cable production, sight is by far more important. Work personnel must distinguish between many colours cables in verifying the cable delivered finally after the machine assembling. Errors are very costly since any nonconformity results in an entire production stock rejection. The luminosity in the production facility is estimated by similitude of different room scales and the necessary of artificial illumination. The results will be computed per the level of illumination indicated for production. A scaled-up estimation will be for the production facility, and is corrected with respect to the production equipment situated between the center of the room, occupied by the directing staff, and the facility edges. Equipment and machines are placed in a visible way from the central area occupied by offices. Results are analysed to improve facility design in terms of rectangularity ratio, colour of the walls, ceiling and floor and light sources emplacement.
\end{abstract}

\section{Introduction}

Sight serves human perceiving the environment reality in proportion of about $90 \%$ of all completed sensorial communication way. Information received by sight is enhanced in specific work conditions, where reactions to visual appearance direct to important decisions, like in driving.

Working with machines represents a peril of being injured by the machine assembles movement. In a phone cable production process, checking cable parameters on the working posts requires good sight abilities, besides good skills 1. Possible hazard management represents a minimum requirement for maintaining the operation of the production 2 .

The right light characteristics that must be in the work area can be satisfied by adequate source lights, well positioned. For normal subjects working, visual perception, contrast sensibility and speed reaction are subject to the absence of shadows, of brilliance or of inadequate light intensity.

Illumination is expressed quantitively in lumen, which represents the light intensity expressed in candles propagated in a solid angle of 1 radian. It is of interest the light flux arrived on a target surface, after possible absorption, reflection or refraction. The light flux is measured in lux, that is 1 lumen reported to 1 square meter. Indirect illumination avoids brilliance of surfaces that makes sight discomfort 3 .

* Corresponding author: cbigan@yahoo.com 
Illumination sources used in the present are halogen bulbs, fluorescent tubes and LED (Light Emitting Diode) tubes, most recently. The halogen bulb replaces the former incandescent bulb, so would primarily serve in household destination; however, it will be considered in the electric sources comparison for the phone cable industrial hall production. The fluorescent tube has an oscillating light source linked to the alternative electric current frequency; this light oscillation is too high to be perceived by the human eye sensor, but induces eye fatigue for repeatedly unconditioned reflex adaptation to this oscillation; fluorescent tubes contain mercury, which is essential for a good light emission. The LED tube is formed of a semiconductor that have its electrons ready to jump on higher energetical levels when excited, emitting light at the same time, in the visible spectrum; the emission is not oscillatory and can be controlled to be on a constant wave length, i.e. constant chromatic 4 .

\subsection{General trends in illuminating facilities}

Illumination quality grows in its importance together with work intensity, sophistication of machine technology and computerized stock evidence. At the same time, the energy consumption is desired to be lowered, even if the source illumination cost would increase, because of electric energy becoming more and more expensive.

The ABB and Philips companies arrived recently at the conclusions that LED bulbs are best for proper illuminations and energy savings, as well. Compared with their old system (not specified, perhaps a not far generation of fluorescent tubes), there is a $12 \%$ reduce in power consumption 5. The illumination level is maintained at a 500-lux level, by combining artificial light with day light. Movement sensors switch off the light gradually, when no more detecting movement after a while. In this adaptive lightening way, a $50 \%$ energy reduce was obtained.

Diehl Metall Schmiedetechnik, company that produces metal-plastic components, arrived to use LED illumination system from the manufacturer Philips, as well 6.

ETAP company from United Kingdom promotes its production of LED illumination tubes for large spaces and high ceilings that can be for production or storage facilities, or for hypermarket products on shelves good illumination display 7 .

Studies of optimal illumination for an existing hall without windows were made in the Transylvanian University from Brasov, Romania. A statistical regression model was used for different source illumination intensity. Again, the conclusion was that if replacing the existing fluorescent tubes with LED tubes, the electric energy consume would reduce to half 8 .

In this paper case, the trend of LED tubes usage should be investigated if it may be a good choice for the phone cable hall production facility ICME ECAB S.A. situated near Bucharest, Romania.

\subsection{Phone cable production}

Phone cables are made of 2 very thin wires, of $0.5 \mathrm{~mm}$ diameter, wrapped in alternative position in a protective sheath. In the case of phone apparatus connectors to cable there are 2, 4,6 or 8 wires to be fixed there 9 .

Every wire has a specific colour that encodes its functionality. Assembling is most often made by alternatively looking carefully in the manual operations guide. Workers must be able to distinguish relatively small type characters on paper, see univocally the wire colours, operate correctly their torsion or verify it after being done by machine and finally fix everything. 
The phone cable lots are rolled on tambours of enormous size, of about 2-3 km of cable. Tambours are of different colours depending on the type of phone cable produced. When the beneficiary receives the goods, selects randomly one tambour category and tests with their apparatus a cable portion randomly, as well. If the test does not fully pass the beneficiary specified requirements in their preliminary offer request, all the same kind tambours are rejected and penalties may apply to the cable producer.
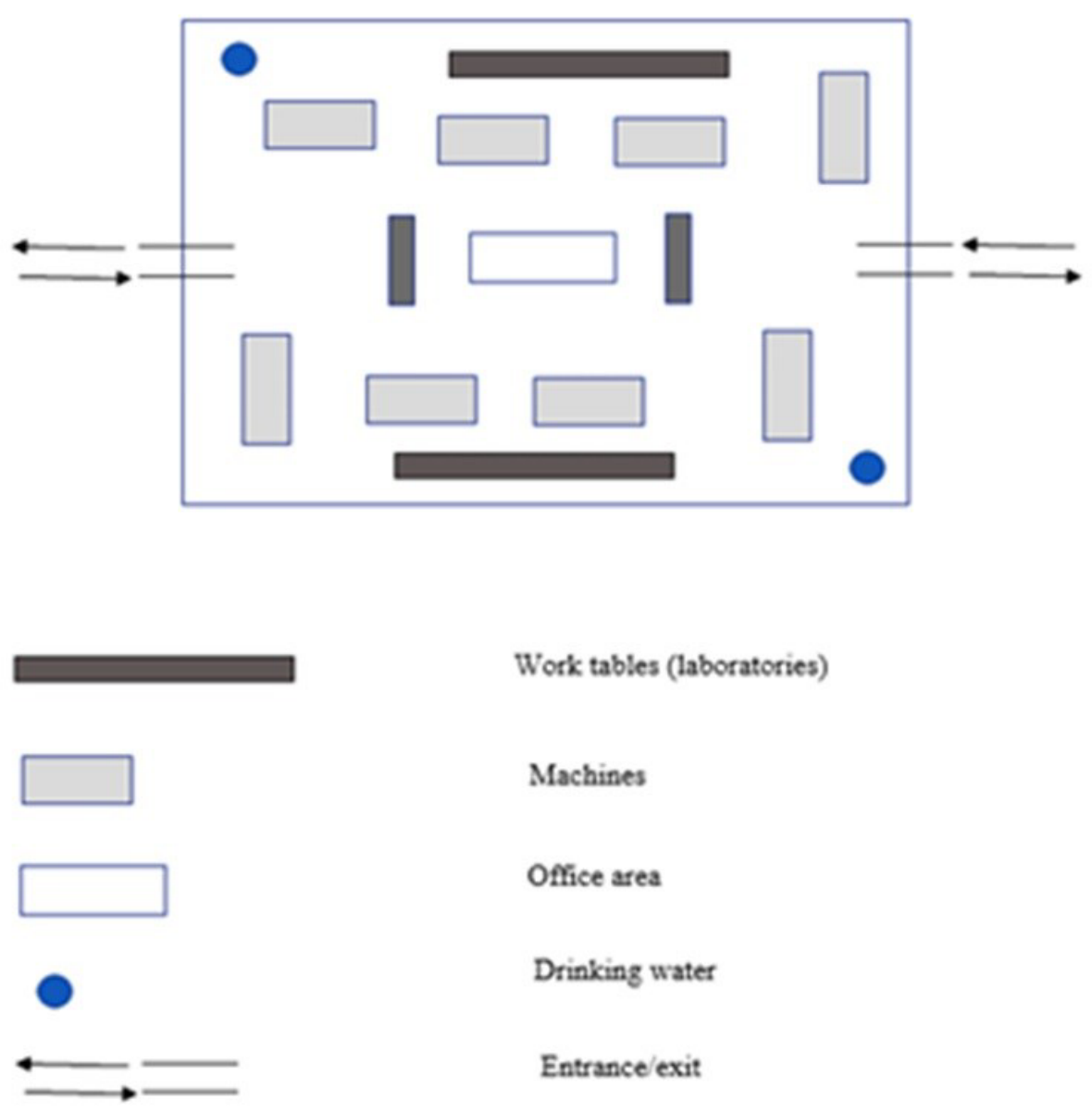

Fig. 1. Phone cable hall production

In these conditions, light required for production purposes must be of a good quality, having the recommended intensity and chromatic characteristics. Comparing the described source lights, oscillatory intensity of fluorescence tubes, even if not detectable by the human sensors may generate fatigue during work and in long practice professional medical problem. LED light sources are still expensive, but have guaranteed constant intensity and wave length of the light. Halogen ECO light sources have been produced as an alternative to classic electric bulbs with incandescence, but probably remain to be used competitively for small interiors. Compact fluorescent tubes may have the light oscillations attenuated, but they are not reported to give a better qualitative light than the LED source. 


\subsection{Cable hall production facility}

The hall has $150 \mathrm{~m}$ of length $L$ and $100 \mathrm{~m}$ of width $W$. It is equipped with all necessary machines to produce desired phone cables, which are packed in large roles (Fig. 1). The principal machines are many extruders for different cables. Cables are twisted in roping machines, in two steps, arriving to 100 elementary cables. Tambours containing up to $2 \mathrm{~km}$ of rolled rope are pushed manually on tracks towards the testing tables, after being put on by cranes. Tables are equipped with testing apparatus of cable fulfilling required parameters; they are serving for studying internal work manuals, as well.

Production is continuously supervised from the hall center, where there is office facility for technical and management production supervision. From there, white collars have a comprehensive view to the blue collars work and machine functioning, and to any personnel access and exit. The office area has 30 meters' length, $l$ and 10 meters' width, $w$.

\section{Illumination method and projection}

Illumination is made sectorial, according to local activities. Not all the machines may be required for use at the same time. Production may work continuously, day and night. To minimize the necessary artificial light requirements, the hall facility was provided with glass transparent walls from ground up to the transversal beam under the ceiling. The ceiling is partially of concrete, partial of glass, to let maximum day light to enter. Artificial light is not provided to adjust automatically to the required light level, however is commanded on the base of decades of experience of working in that facility.

There are analysed one by one the illuminating devices available for providing the necessary light all over the hall production. The calculus steps start in estimating the necessary luminosity for good work in the facility. One of the work nature is of machine working, supervising and checking or repairing, necessity of know-how handling, but as well fixing small landmarks in cable manufacturing machines. For this kind of operations, the necessary source light intensity is between 300 and $750 \mathrm{~lx}$. Other operation is of making precise measurements for testing the fabricated cable. For laboratory kind operations, a higher source light intensity between 500 and $1000 \mathrm{~lx}$ is required, stipulated by on rule normative. Since both types of operation occur equally frequently, a mean light intensity $i_{p}$ of $625 \mathrm{~lx}$ would be set to fulfil the requirements. This illumination level is not affecting the office area, which is isolated by non-transparent roof and by glass walls from the rest of the hall; there, the required level is between 220 and $370 \mathrm{~lx}$ for working both on paper and on LCD screen, luminosity assured by separate desk and low ceiling illumination; considering increased visual tasks during being in service, an $i_{o}$ of 320-lx light intensity will be selected for a majority human subjects eye comfort 10 .

The illumination surface $S$ will be divided between production area, $S_{p}$ and office area, $S_{o}$ :

$$
\begin{gathered}
S_{o}=l \cdot w=30 \cdot 10=300 \mathrm{~m}^{2} \\
S=L \cdot W=150 \cdot 100=15.000 \mathrm{~m}^{2} \\
S_{p}=S-S_{o}=15.000-300=14.700 \mathrm{~m}^{2}
\end{gathered}
$$

The total light $Q$ is the sum of the light for the production area $Q_{p}$ and the light for the office area $Q_{o}$ :

$$
Q_{p}=i_{p} \cdot S_{p}=625 \mathrm{~lx} \cdot 14.700 \mathrm{~m}^{2}=9.187 .500 \mathrm{~lm}
$$




$$
\begin{gathered}
Q_{o}=i_{o} \cdot S_{o}=320 \mathrm{~lx} \cdot 300 \mathrm{~m}^{2}=96.000 \mathrm{~lm} \\
Q=Q_{p}+Q_{o}=9.283 .500 \mathrm{~lm}
\end{gathered}
$$

The rectangularity ratio does not influence the light requirement since its source propagates almost vertically by spreading enough the cross area light flow to cover entirely the floor. In this way, shades practically are not present, light arriving on all machine surfaces that are placed equally distanced between office area and hall edges 11 .

As it is in present reality, the hall production walls are entirely of transparent glass. This may be replaced with another glass type, which has special properties of entirely permitting day light to enter and letting little to pass from the hall outside, especially during dark light occurrence. Besides light preserve, nobody from outside can look in the hall facility. Glass walls are doing economy tasks for electric energy consuming, for lightening reasons and to filter at the same time in the very sunny day lights, avoiding greenhouse effect especially during hot days.

The floor and the ceiling would be preferred in light colours that are most reflective in terms of light. The ceiling would be painted of an anti-static white. The floor would be of massive granite resistant and vibration absorbent polished surface covered by an eye comfortable light brown colour 12.

Light sources are mounted on the ceiling since the light intensity projection refers to the light source position to be on the top position, up oriented to reflect the light down without shadows. There are four types of light sources considered for comparing: LED, fluorescent tube, compact fluorescent tube, and ECO halogen light source. All sources will be considered to maximum possible power to reduce their number to the minimum. The case of light sources mixing is excluded first to avoid eye shock caused of abruptly adapt necessity to light variations, and of technological sources mounting and maintenance 13. A different light source may be considered for the office area, if benefit found. The total light necessity computed in relation (6) will be considered, rounded to an upper number as multiple of 25 to have integer result on hall length $L$ and width $W$. Any light source is supposed to be replaced at about two of third times the reported functioning time to avoid production dysfunctionalities because of lower light performances, and to avoid short circuits due to longer use associated with fire hazards 14 . The consumed electric energy is considered at $c_{\text {elen }}=0,40 \mathrm{lei} / \mathrm{kWh}$, TVA included.

\subsection{LED tube}

LED source light is available to a maximum power of $w_{L E D}=12 \mathrm{~W}$ for each source, maximum producing 1070 lumen. The number of LED source light required is:

$$
n_{L E D}=\frac{Q}{1070} \cong 8700
$$

One LED is reported to cost $c_{L E D}=49,30$ lei and to last about $t_{L E D}=50.000 \mathrm{~h} 15$. The mounting and maintenance cost for each LED is estimated at $m_{L E D}=5$ lei. The hourly cost of illumination $P_{L E D}$ would be: 


$$
\begin{aligned}
& P_{L E D}=n_{L E D} \cdot\left[\frac{c_{L E D}+m_{L E D}}{t_{L E D} \cdot \frac{2}{3}}+\left(\frac{w_{L E D}}{1000}\right) \cdot c_{\text {elen }}\right] \\
= & 8700 \cdot\left[\frac{49,3+5}{5 \cdot 10^{4} \cdot \frac{2}{3}}+\left(\frac{12}{1000}\right) \cdot 0,4\right]=55,94 \mathrm{lei} / \mathrm{h}
\end{aligned}
$$

The surface covered by each LED is:

$$
S_{L E D}=\frac{S}{n_{L E D}}=\frac{15000}{8700}=1,72 \mathrm{~m}^{2}
$$

\subsection{Fluorescent tube}

Fluorescent tube source light is available to a maximum power of $w_{f l t}=36 \mathrm{~W}$ for each source, maximum producing 3350 lumens. The number of sources light required is:

$$
n_{f l t}=\frac{Q}{3350} \cong 2800
$$

The unit cost is $c_{f l t}=19,04$ lei and to last about $t_{f l t}=30.000 \mathrm{~h} 16$. The mounting and maintenance cost for each piece is estimated at $m_{f l t}=10 \mathrm{lei}$, since the manipulation is more difficult and there is a peril of mercury contamination in case of breaking by mistaken. The hourly cost of illumination $P_{f l t}$ would be:

$$
\begin{aligned}
& P_{f l t}=n_{f l t} \cdot\left[\frac{c_{f l t}+m_{f l t}}{t_{f l t} \cdot \frac{2}{3}}+\left(\frac{w_{f l t}}{1000}\right) \cdot c_{\text {elen }}\right]=2800 \cdot\left[\frac{19,04+10}{3 \cdot 10^{4} \cdot \frac{2}{3}}+\left(\frac{36}{1000}\right) \cdot 0,4\right] \\
& =44,39 \text { lei } / \mathrm{h}
\end{aligned}
$$

The surface covered by each fluorescent tube is:

$$
S_{f l t}=\frac{S}{n_{f l t}}=\frac{15000}{2800}=5,36 \mathrm{~m}^{2}
$$

\subsection{Compact fluorescent tube}

The maximum power is of $w_{c f t}=25 \mathrm{~W}$ for each source, maximum producing 1520 lumens. The number of sources light required is:

$$
n_{c f t}=\frac{Q}{1520} \cong 6125
$$

The unit cost is $c_{c f t}=44,18$ lei and to last about $t_{c f t}=10.000 \mathrm{~h}$. The mounting and maintenance cost for each piece is estimated at $m_{c f t}=5$ lei. The hourly cost of illumination $P_{c f t}$ would be: 


$$
\left.\begin{array}{c}
P_{c f t}=n_{c f t} \cdot\left[\frac{c_{c f t}+m_{c f t}}{t_{c f t} \cdot \frac{2}{3}}+\left(\frac{w_{c f t}}{1000}\right) \cdot c_{\text {elen }}\right] \\
=106,44 \mathrm{lei} / \mathrm{h}
\end{array}\right]=6125 \cdot\left[\frac{44,18+5}{10^{4} \cdot \frac{2}{3}}+\left(\frac{25}{1000}\right) \cdot 0,4\right]
$$

The surface covered by each fluorescent tube is:

$$
S_{f l t}=\frac{S}{n_{f l t}}=\frac{15000}{6125}=2,45 \mathrm{~m}^{2}
$$

\subsection{Eco halogen bulb}

The maximum power is of $w_{\text {ech }}=105 \mathrm{~W}$ for each source, maximum producing 1900 lumens. The number of sources light required is:

$$
n_{\text {ech }}=\frac{Q}{1900} \cong 4900
$$

The unit cost is $c_{e c h}=5,95$ lei and to last about $t_{e c h}=2.000 \mathrm{~h}$. The mounting and maintenance cost for each piece is estimated at $m_{e c h}=2$ lei, since it is a very simple work procedure. The hourly cost of illumination $P_{e c h}$ would be:

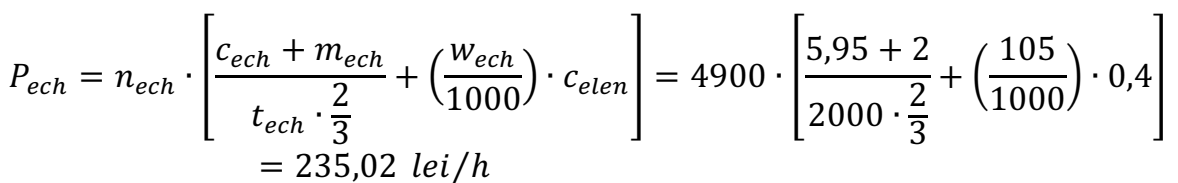

The surface covered by each fluorescent tube is:

$S_{f l t}=\frac{S}{n_{f l t}}=\frac{15000}{4900}=3,06 \mathrm{~m}^{2}$

\section{Results and discussion}

The estimation hourly cost for lightening the industrial production hall helps to easily eliminate the halogen ECO bulbs and the compact fluorescence tubes that have sensibly much greater exploit costs than LED tubes or common fluorescent tubes. However, it is to consider the eye fatigue from oscillating intensity light emission for the fluorescent tubes and the mercury intoxication peril in case of mishandling them correctly. The LED tube exploit price is not far from the fluorescence tube and would be preferred even if it is of about $25 \%$ more expensive. The LED tube illumination has the advantage of a higher emplacement density having the illumination task of deserving only 1.72 square meters of ceiling; this is a value that would avoid object placed on the ground and human body shade and that can be focalised on the designed surface without interference between two next situated LED tubes. At the same time, the illumination from LED tubes is most recommended for desk office tasks, so they can be used in all the hall facility. 
It is noticeable that the cost advantage of using LED tubes instead of fluorescent tubes is not so evident, as presumed. The obtained result is dependent on right data to be used for. The final decision would be influenced by technological and economic reasons that would give in each case one or another result between the two nearly priced electric sources, LED tubes and fluorescent tubes.

\section{Conclusions}

A phone cable manufacturing facility was studied regarding the illumination options in the required parameters of technology specificity. The hall production facility was designed in terms of active areas emplacement inspired from information and experience of profiled engineers who had worked in such a facility for their entire active life. Four current used light sources, LED tubes, fluorescent tubes, compact fluorescent tubes and ECO halogen bulbs were compared in terms of hourly cost if assuring the all calculated necessary light for this specific production activity. The analysis proved useful in technically eliminating the non-economically efficient source lights, despite of their lower acquisition cost. It is foreseen a deepening of the study by obtaining additional information directly from the plant's leadership.

\section{References}

1. V. Lefter, A. Manolescu, A. Deaconu, Ergonomie (Editura Economica, 2010)

2. R.I. Moraru, G.B. Băbuţ, L.I. Cioca, Environmental Engineering and Management Journal 13, 6 (2014)

3. A. Draghici, Ergonomie (Editura Regie, 2009)

4. $* * *$ https://www.magazin-leduri.ro/beneficiile-iluminatului-led-vs-iluminat-fluorescent/, accessed 12.03.2017

5. ABB, www.abb.com/lowvoltage, accessed 12.03.2017

6. Diehl Metall Scmiedetechnik, http://www.diehl.com/en/diehl-group.html, accessed 12.03.2017

7. ETAP NV, www.etaplighting.com, accessed 12.03.2017

8. C. Chis, Student Scientific Research Yearbook of the Transylvania University Brasov 65-68, (2015)

9. $* * * \mathrm{http}: / /$ cabluri.net/telefonice/, accessed 12.03.2017

10. $* * *$ http://www.misiuneacasa.ro/uploads/files/normative4.pdf, accessed 12.03 .2017

11. *** http://www.rabalux.com/ro_RO/calculator-al-nivelului-de-iluminare, accessed 12.03.2017

12. A. Muresan, http://www.tex.tuiasi.ro/biblioteca/carti/CURSURI/Prof.\%20Dr.\%20Ing.\%20Augustin \%20Muresan/Curs\%2014.\%20Evaluarea\%20culorii.pdf

13. *** http://ebooks.unibuc.ro/StiinteADM/enache/24.htm, accessed 12.03.2017

14. L.I. Cioca, R.I. Moraru, Archives of Mining Sciences 57, 1 (2012)

15. $* * * \mathrm{https} / / / \mathrm{www}$.magazin-leduri.ro/eficacitatea-si-durata-de-viata-a-becurilor-led/, accessed 12.03.2017

16. $* * *$ http://lightsmart.ro/blog/tuburi-led-versus-tuburi-fluorescente-consideratiuni-generale/, accessed 12.03.2017 